\title{
Transgenerational accumulation of methylome changes discovered in commercially reared honey bee (Apis mellifera) queens
}

\author{
Zhijiang ZENG ${ }^{1}$, YAO YI ${ }^{1}$, Xujiang $\mathrm{HE}^{1}$, Andrew BARRON², Yi bo Liu $^{3}$, Zi Long Wang ${ }^{1}$, \\ and Wei Yu Yan ${ }^{1}$ \\ ${ }^{1}$ Jiangxi Agricultural University \\ ${ }^{2}$ Macquarie University \\ ${ }^{3}$ Affiliation not available
}

May 5, 2020

\begin{abstract}
Whether a female honey bee (Apis mellifera) develops into a worker or a queen depends on her nutrition during development, which changes the epigenome to alter the developmental trajectory. Beekeepers typically exploit this developmental plasticity to produce queen bees by transplanting worker larvae into queen cells to be reared as queens, thus redirecting a worker developmental pathway to a queen developmental pathway. We studied the consequences of this manipulation for the queen phenotype and methylome over four generations. Queens reared from worker larvae consistently had fewer ovarioles than queens reared from eggs. Over four generations the methylomes of lines of queens reared from eggs and worker larvae diverged, accumulating increasing differences in exons of genes related to caste differentiation, growth and immunity. We discuss the consequences of these cryptic changes to the honey bee epigenome for the health and viability of honey bee stocks.
\end{abstract}

\section{Hosted file}

Manuscript.pdf available at https://authorea.com/users/300673/articles/430369transgenerational-accumulation-of-methylome-changes-discovered-in-commercially-rearedhoney-bee-apis-mellifera-queens 